\title{
A importância da imigração haitiana na concepção da nova Lei Municipal ( São Paulo) de migração
}

\author{
Priscilla Pachi *
}

\section{Introdução}

Desde 2014, estou engajada num trabalho voluntário que consiste em palestras de conteúdo intercultural para os imigrantes e refugiados de língua francesa na Missão Paz ${ }^{1}$ em São Paulo. A partir desse ano, tive a oportunidade de acompanhar a chegada dos imigrantes haitianos que, naquela época, vinham em grande número para o Brasil em busca de um novo início para suas vidas prejudicadas por uma sucessão de acontecimentos de ordem política, econômica, social e geológica. Segundo o Ministério da Justiça, $43.781^{2}$ haitianos entraram no Brasil pela fronteira do Acre de 2010 a 2015. A situação vivenciada por estes imigrantes em São Paulo me permitiu formular algumas indagações com relação à sua importância no contexto dos movimentos migratórios atuais e o papel que exerceram para que mudanças pudessem ocorrer no tocante à tramitação e aprovação da primeira Lei Municipal de Migração em São Paulo-SP.

O presente artigo tem por objetivo fazer uma breve análise da atuação do Estado, da sociedade civil (ONGs, dos próprios imigrantes e dos envolvidos com a causa dos imigrantes) e o papel exercido pela imprensa que foram fundamentais para a aprovação da Lei Municipal de Migração 16.478/2016 de 08 de julho de 2016 e pela tramitação da nova Lei Federal de Migração no. 13.445/17 recentemente aprovada pela Câmara e pelo Senado federais e sancionada com vinte vetos.

Cabe ressaltar que os imigrantes haitianos não tiveram uma participação direta para a elaboração e o desfecho das leis junto aos órgãos públicos, mas de forma indireta estes imigrantes foram fundamentais para que grandes mudanças no campo jurídico pudessem ocorrer.

\section{Breve relato sobre a migração haitiana para o Brasil}

O intenso fluxo migratório de haitianos para o Brasil é recente e seu aumento é comumente associado ao terremoto que destruiu Porto Príncipe, capital do

\footnotetext{
* Mestranda do Programa de Pós-Graduação em Geografia Humana da Faculdade de Filosofia, Letras e Ciências Humanas da Universidade de São Paulo
} 
Haiti, em 2010, impondo severas limitações à sobrevivência e subsistência de seus habitantes. De acordo com Cotinguiba (2014), o terremoto tornou-se argumento explicativo do governo brasileiro e foi reforçado pela mídia de modo geral. Fato é que a entrada desses imigrantes no país intensificou-se em 2011 e 2012.

Segundo Germani (1974), é necessário ter como parâmetro para análise dos processos migratórios não somente os fatores de repulsão e de atração que levam contingentes populacionais a procurarem outros lugares para se fixarem. Deve-se considerar, nesta perspectiva, condições sociais, culturais e subjetivas tanto no país de origem quanto no destino, isto é, no sistema como um todo. As migrações são fenômenos complexos com reflexos que afetam tanto as áreas receptoras como as de êxodo. Sua compreensão requer análise de elementos sociais, políticos, culturais, ambientais e territoriais, não havendo uma teoria unificadora ou que dê conta das várias dimensões e processos que necessitam de explicação (ARANGO, 2000).

Na perspectiva brasileira, a primeira década do século XXI é marcada por uma ampliação da inserção internacional do país e por um crescimento econômico propiciado pela estabilidade institucional e pela alta do preço das commodities no mercado internacional. A maior inserção internacional do Brasil tem como exemplo sua atuação no Haiti. Além do Brasil liderar a Missão das Nações Unidas para a Estabilização do Haiti (MINUSTAH) desde 2004, organizações brasileiras como Pastoral da Criança, Grupo de Apoio à Prevenção da Aids (GAPA) e empresas como a Embrapa passaram a atuar no país caribenho, o que teria motivado o aumento do interesse pelo Brasil por parte dos haitianos. Pode-se dizer que o discurso do crescimento econômico associado às possibilidades de trabalho e a relativa facilidade para a concessão de visto sejam atrativos para os haitianos. Somem-se $a$ isso as restrições à imigração em outros países da América do Norte e da Europa, como aponta Cotinguiba (2014).

Atualmente, o quadro econômico e político do Brasil é bem diferente do que foi prometido e divulgado pelo governo e a imprensa, e encontrado pelos haitianos anos atrás. Com a economia brasileira em desaceleração, investimentos estrangeiros estão sendo retirados do país e uma crise política e econômica afeta os empregos, o consumo e a dignidade das pessoas.

\section{O espaço como produto de relações sociais e econômicas}

Até a década de 1960, o Estado parecia ser a instituição política e social dominante que governava e dirigia a sociedade. Nos Estados industriais ocidentais avançados acreditava-se que a administração econômica nacional poderia continuar a garantir tanto o pleno emprego quanto o crescimento relativamente constante da economia. As revoluções de 1989, no Leste Europeu, e suas consequências levaram a uma ampla percepção do mundo moderno e da perda de governabilidade única dos Estados-nação que cederam sua supremacia econômica nacional aos interesses globais. 
Com a globalização o Estado-nação deixou de ser um administrador econômico efetivo, tornou-se menos autônomo, com menos controle exclusivo sobre os processos econômicos e sociais dentro de seu território e menos capaz de manter a homogeneidade cultural.

A perda da capacidade única de governabilidade não extinguiu do Estado o controle de seu território e a regulação das populações; ele permanece um controlador de suas fronteiras e do movimento das pessoas que as cruzam. É o Estado que define quem é ou não é cidadão, quem pode ou não receber assistência do governo. Mesmo com movimentos migratórios cada vez maiores, as pessoas ainda são menos móveis que o dinheiro, permanecem "nacionalizadas" e dependentes de passaportes, vistos, residências e qualificações de trabalho. O migrante trabalhador se move em busca de trabalho, melhores condições de vida e, muitas vezes, acaba se fixando em outros países ou retornando ao seu país de origem após o fim de um período de trabalho devido à garantia que somente o seu país o concede, ou seja, a documentação e sua nacionalidade. Neste sentido, os Estados continuam soberanos porque policiam os limites de seus territórios e, à medida que são democráticos, são representativos dos cidadãos em suas fronteiras.

A mobilidade de grupos humanos para atender à necessidade dos arranjos produtivos configura uma nova divisão social do trabalho. Santos e Silveira (2012, p. 21-22) nos lembram que a divisão territorial do trabalho cria uma hierarquia entre lugares e redefine, a cada momento, a capacidade de agir das pessoas, das firmas e das instituições. Além disso, o território condiciona a localização dos atores pois, as ações que sobre ele operam dependem da sua própria constituição. Abre-se desse modo a possibilidade de discussão da imigração relacionada ao trabalho e às demandas do capital por mão de obra disponível e de baixo custo, associadas a processos de territorialização e inserção social.

Com a economia globalizada, o Estado, por si só, já não tem mais força para ser o único ator que incide diretamente nas políticas públicas. 0 novo cenário organizacional exige uma complexa negociação com as organizações. 0 pluralismo jurídico, cada vez maior e abrangendo mais áreas socioeconômicas, diminui a ação do Estado como único ator político e jurídico no território. Neste cenário, além das instituições, várias Organizações não governamentais (ONGs), com poder e atuação civil, surgem para suprir algumas das funções elementares do governo, tais como a educação e o combate a fome em Estados-nação fracos e ineficientes. Essas organizações também possuem força e influência jurídica junto ao governo.

Tem sido atribuído à Geografia a responsabilidade de estudar o espaço, na forma de espaço habitado, transformado e utilizado pelo ser humano e pela sociedade, como instância social. O espaço configura- se no campo da reprodução das relações sociais, econômicas, políticas e culturais marcadas por conflitos e contradições que resultam na ocupação e desocupação de áreas e, consequentemente, na mobilidade dos grupos humanos. Assim sendo, o espaço é o objeto de estudo dessa ciência. Além disso, alguns autores têm contribuído 
para o debate conceitual com relação ao espaço para a Geografia, inclusive alguns não geógrafos, como é o caso de Henri Lefebvre (2004).

Henri Lefebvre (2004) concebe o espaço como o lugar da reprodução das relações sociais de produção, isto é, da reprodução da sociedade. Por este entendimento, o espaço deve ser concebido como espaço social, espaço vivido, relacionado à prática social e não apenas como produto da sociedade. $O$ espaço assume a dimensão de construção social que aborda as relações humanas e o tempo histórico. A construção do espaço se dá por meio de uma sociedade que o vive. Deste modo, ele não pode ser homogêneo. É por meio do espaço que compreendemos as dinâmicas da sociedade que se expressam nos diversos lugares.

Carlos (2011) nos aponta a produção do espaço como categoria indispensável para a ciência geográfica sendo uma realidade histórica da humanidade enquanto condição, meio e produto da reprodução social. Para Martins (2014), somos todos (imigrantes ou não) vítimas de processos econômicos, sociais e políticos excludentes. Para este autor não existe desterritorialização porque não há homem sem território, mas diversas formas dele ocupá-lo precariamente.

No caso do Haiti, sabemos que após uma série de conflitos políticos e sociais e com o país abalado por um terremoto, as necessidades básicas da população não puderam mais ser atendidas, o que forçou a população a buscar alternativa na emigração. Os haitianos partem para o Brasil em busca de melhores condições de vida, buscam um emprego e remetem a maior parte de seus salários, que são convertidos em dólares, para as suas famílias. No entanto, ao chegarem no Brasil, integram as dinâmicas territoriais e sociais brasileiras e descobrem que a manutenção da vida e a inserção no mercado de trabalho não condizem com as expectativas que tinham antes da partida. A dificuldade de encontrar emprego frente à uma crise política e econômica aprofunda o problema da precariedade das condições de vida e de trabalho que se reproduzem no espaço da metrópole paulistana.

Devemos ainda nos valer de instrumental teórico que nos permita compreender a imigração haitiana à luz dos processos de reprodução capitalista. Como o trabalho é um fator determinante para a territorialização desses imigrantes, é necessário estabelecer os vínculos entre migração, trabalho e reprodução do espaço. Imigração e trabalho se tornam aspectos complementares na visão de Sayad (1998). Para este autor, a permanência de um imigrante em determinado local só se justifica enquanto houver trabalho e ele assumir a posição que se espera dele na sociedade que o recebe, ou seja, de um trabalhador necessário e capaz de suprir as demandas existentes no mercado de trabalho. Da mesma forma, Harvey (2005) afirma que a expansão do capital para além dos territórios leva à imigração. A grande quantidade de mão de obra disponível pode ser aproveitada se houver deslocamentos de grupos, que por sua vez buscam trabalho e melhores condições de vida. Deste modo, a metrópole paulistana, apesar da crise, ainda oferece emprego. 


\section{Estatuto do Estrangeiro}

A lei que até hoje (até novembro de 2018) rege o imigrante no Brasil é o "Estatuto do Estrangeiro", Lei 6.815 de 1980, um dos resquícios da ditadura militar (1964-1985) que considera o refugiado e o imigrante como um risco à segurança nacional e à população, impondo inclusive limites à liberdade.

O Estatuto do estrangeiro, na prática, acaba sendo um impeditivo para o exercício do direito ao deslocamento pelo território brasileiro e ao tratar o imigrante como ameaça, o criminaliza, relegando-o a uma situação precária e dando margem à práticas de xenofobia, preconceito e racismo. A partir do momento que tal lei não reconhece a dignidade do imigrante, também o proíbe de participar de organizações/associações, sindicatos e da política.

Atualmente quem é responsável por todo o trato e trâmite da imigração é a Policia Federal que criminaliza a questão migratória e não consegue tratar o imigrante com dignidade devido à sua própria natureza. Nesse sentido, é antiga a percepção de que a Policia Federal, embora possua importantes competências em matéria de segurança, que exigem a sua presença nos pontos de entrada e de saída do país, não é a instituição mais adequada para administrar as políticas de autorização de entrada e permanência de imigrantes no Brasil.

Apesar da Constituição Brasileira ser posterior ao Estatuto do Estrangeiro, a Polícia Federal e as escolas ainda o aplicam para tratar o imigrante. O Estatuto do Estrangeiro possui alto grau de burocratização que dificulta a regularização migratória da pessoa que entrou no território nacional sem o visto ou que se tornou irregular depois da expiração deste. Cabe ressaltar que a irregularidade migratória implica diretamente no não acesso aos direitos básicos. Isto deixa os imigrantes numa condição social ainda mais vulnerável, sobretudo no que se refere à exploração da sua força de trabalho.

Logo, pensar em uma nova lei de migração e nos responsáveis por tratar o tema é pensar em incluir os imigrantes e refugiados em políticas públicas que Ihes integrem de maneira digna na sociedade.

\section{Participação da sociedade civil e de movimentos sociais: uma nova gestão na cidade de São Paulo}

Fernando Haddad, prefeito da cidade de São Paulo no período de 01/2013 a $01 / 2017$, desde a sua campanha se reuniu com os imigrantes e comprometeuse a criar uma política migratória. $O$ primeiro passo dado para que isso pudesse ocorrer foi em agosto de 2013 com a criação de uma secretaria de Direitos Humanos e dentro dela uma Coordenadoria de Políticas para Migrantes (CPMIG) que surgiu a partir da necessidade de acolhimento dos imigrantes, sobretudo haitianos, que chegavam à cidade. A criação da coordenação foi uma mudança importante de paradigma, pois retirou o tema da imigração do âmbito da 
segurança nacional, como está expresso no Estatuto do Estrangeiro (1980), e o colocou na esfera dos direitos humanos. Sua atuação é pautada pelo diálogo com associações e comunidades de imigrantes, em busca de consolidar uma política para imigrantes que seja fruto da participação e das reivindicações dos mesmos.

Em 2013 foi realizada a 1a Conferência Municipal de Políticas para Imigrantes, cuja meta da gestão seria a participação da sociedade civil, associações, governo do Estado e Federal nos debates, tendo em vista que todos têm responsabilidades neste assunto e o objetivo comum de contribuir na elaboração de propostas e diretrizes para subsidiar as políticas públicas voltadas à população imigrante e suas famílias. A partir de então, o imigrante passou a ser visto como sujeito e foi chamado para o Conselho Participativo da cidade. Desses encontros surgiram várias propostas que alimentaram o debate e o monitoramento dos compromissos assumidos pela prefeitura.

Em abril de 2014, a cidade de São Paulo recebeu 1.900 haitianos que chegavam do Acre sem aviso prévio das autoridades daquele estado. Surgiu a partir deste episódio o desafio de construir centros de referência e de acolhimento para os imigrantes. Este projeto já estava previsto, mas devido a situação emergencial daquele momento, a prefeitura de São Paulo-SP entregou, após três meses, o primeiro centro na Bela Vista com todo o suporte necessário ao imigrante como assistentes sociais, aulas de português e apoio jurídico.

Cabe ressaltar que a maioria dos imigrantes que chegam a São Paulo usam a cidade como trânsito para outros países ou outros estados da federação. Logo, os centros de referência são de extrema importância para o acolhimento dessas pessoas. Além disso, esses centros não foram criados somente para os haitianos, mas a necessidade de recebê-los e acolhê-los de forma emergencial fez com que os projetos saíssem do papel e fossem rapidamente entregues.

Em setembro de 2015, por inciativa da Prefeitura de São Paulo, ocorreu a primeira reunião de abertura dos trabalhos para elaboração do Projeto de Lei Municipal 142/2016 para migrantes. O processo de elaboração da Lei Municipal foi realizado por meio do Comitê Intersetorial da Política Municipal para a População Imigrante, criado pelo Decreto Municipal no 56.353 , formado por 26 integrantes, sendo treze representantes do poder público, treze integrantes da sociedade civil e teve o papel de promover e articular as políticas públicas migratórias no município de forma transversal e sob a ótica do imigrante.

As propostas elaboradas pelo grupo foram transformadas em um Anteprojeto de Lei e validadas por meio de consulta pública, antes de seguirem para discussão na Câmara Municipal e, posteriormente, para sanção do então prefeito Fernando Haddad. O projeto foi assinado na presença de vários imigrantes e representantes da sociedade civil organizada. O PL 142/2016 contém dez artigos cujo objetivo é institucionalizar as políticas públicas voltadas aos migrantes e que foram criadas nos últimos anos, transformando-as em um compromisso do poder público municipal, independente da gestão administrativa. 
O PL142/2016 passou a ser denominado Lei Municipal 16.478/2016 de julho de 2016. Com isso, a Prefeitura do Município de São Paulo aprovou a primeira lei municipal de migração do país que institui diretrizes para a política migratória em âmbito municipal. Com a nova Lei, a cidade de São Paulo passa a tratar a situação migratória a partir dos direitos e da dignidade dos imigrantes.

\section{O papel da imprensa}

O Ministério da Justiça ${ }^{3}$ indica que 43.781 haitianos entraram no país de janeiro de 2011 a julho de 2015 . Os haitianos ultrapassaram os portugueses em 2013 e tornaram-se o maior grupo de estrangeiros com vínculo formal de trabalho no Brasil ${ }^{4}$. Este dado seria um motivo de comemoração para a comunidade haitiana no Brasil se não houvessem tantos problemas vinculados à esta imigração.

Na sua maioria, os haitianos chegavam pelo Acre e pelo Amazonas e se destinavam, posteriormente, aos Estados das respectivas Regiões Sul, Sudeste e Centro-Oeste. A intensidade e a regularidade do seu fluxo migratório chamaram atenção da opinião pública e dos meios de comunicação, que focaram sua atenção no despreparo do Brasil para o trato da questão imigratória. 0 debate público não explora as dinâmicas sociais e multifatoriais envolvidas no estabelecimento de uma corrente imigratória. Tampouco são problematizados os funcionamentos das sociedades envolvidas neste processo.

No entanto, tal debate trouxe para o centro das preocupações a questão imigratória. Desde o encerramento da chegada em massa de europeus ao Brasil na segunda metade do século $X X$, a opinião pública se concentrava na discussão da emigração de brasileiros devido às inúmeras crises sociais e econômicas enfrentadas pelo Brasil ao longo dos anos 1980 e 1990. A inserção do Brasil pelos haitianos em sua rota migratória, que, conforme aponta Cotinguiba (2014) não é um fenômeno recente e ocorre de forma constante há pelo menos um século, torna-se uma novidade para a população, os meios de comunicação e o país. $\mathrm{O}$ ineditismo do aumento do fluxo imigratório haitiano aliado ao fomento da mídia que retratou tal movimento, principalmente o da chegada em São Paulo, somente de forma negativa e pejorativa no que diz respeito aos haitianos, incitou reações de racismo e xenofobia condensada na figura desses imigrantes. Cabe ressaltar que no mesmo período citado acima, entraram no Brasil mais europeus do que haitianos. Contudo, não se falou ou publicou sobre isso.

$\mathrm{O}$ fato é que a partir dos relatos negativos da imprensa juntamente com algumas reações extremas e xenófobas da população, os haitianos tomaram a cena e isso criou uma pressão muito grande para que os governos, principalmente o da cidade de São Paulo, buscassem soluções rápidas de acolhimento e assistência para os imigrantes que chegavam cada vez mais em número maior.

O papel da imprensa também foi fundamental na propagação de boas notícias sobre o Brasil e sua economia no início dos anos 2000. Essas notícias de que a nossa economia mostrava-se saudável e a atuação do Estado e de 
empresas brasileiras no Haiti foram responsáveis por criarem um imaginário de ganhos fartos e melhores condições de vida no Brasil. As comunicações modernas formam a base de uma sociedade civil internacional, na qual os povos compartilham interesses e as associações cruzam fronteiras. A mídia internacional também possibilita que uma série de culturas cosmopolitas e nacionais interaja e se propague por meio de uma propaganda positiva ou negativa. No caso da mídia brasileira, a propaganda positiva sobre a economia do país atraiu vários haitianos e outros imigrantes que viram no Brasil a grande possibilidade de um recomeço promissor.

\section{Sociedade civil organizada}

O Projeto de Lei (PL 142/2016) entregue à Câmara Municipal de São Paulo é resultado de um longo processo de discussão entre poder público e a sociedade civil, englobando reivindicações antigas das comunidades de imigrantes e organizações relacionadas com a temática migratória. A partir de agosto de 2015, o processo ganhou caráter institucional com a formação do Comitê Intersetorial da Política Municipal para a População Imigrante. Ocorreram várias reuniões deste comitê na prefeitura e na secretaria de direitos humanos para trazer as demandas e contribuições da população migrante, ONGs e entidades que trabalham com migração (Missão Paz, Caritas, Conectas, Sefras, PAL, SPM - Serviço Pastoral dos Migrantes, entre outras) e os conselheiros participativos municipais atuaram junto aos vereadores para aprovarem a lei.

Diversas organizações autônomas, ligadas às pastorais ou ao poder público vêm crescendo. Essas organizações tomaram para si a responsabilidade de, por um lado, lutar pelos direitos dessas populações migrantes por meio de práticas de atendimento jurídico, acolhimento e promoção de práticas de socialização, cultura e educação, como é o caso da Missão Paz e da Caritas. Foi este grupo que organizou o documento inicial para compor a lei, incluindo as contribuições feitas durante consultas públicas presenciais e pela internet.

Uma marcha por direitos acontece anualmente na cidade de São Paulo, no mês de dezembro, como parte do calendário de luta internacional dos migrantes e refugiados. Durante a marcha é realizada uma série de reivindicações como: a necessidade de uma nova lei de migração, trabalho decente, direito ao voto, educação, saúde sem discriminação, e cidadania plena. A marcha retrata a complexidade da realidade da vida da população imigrante em São Paulo e expõe um conjunto extenso de violações que fazem com que imigrantes e refugiados vivam sob uma condição de quase não cidadania.

\section{Nova Lei Federal de Migração no. 13.445/17}

Além da participação da sociedade civil paulistana para a conquista e pioneirismo na elaboração e aprovação de uma lei municipal que trate a 
migração, tivemos mais uma grande conquista em maio de 2017, ou seja, a Lei 13.445/17 sancionada pelo Presidente Michel Temer e que substitui o Estatuto do Estrangeiro. Vale observar que a sociedade civil (representada pelas mesmas ONGs e instituições de São Paulo e pelos imigrantes de todo o Brasil) acompanhou todas as etapas, inclusive com proposições, até o texto final adotado em julho de 2016 pela Comissão Especial da Câmara dos Deputados. Há anos as dificuldades enfrentadas pelos imigrantes no país são apontadas pelas organizações da sociedade civil que atuam diretamente com essa população.

A Lei 13.445/17 representa uma enorme mudança ao olhar para o imigrante do ponto de vista dos direitos humanos. Ao fazer isso, supera vários problemas da legislação atual. No entanto, a versão final teve 20 artigos vetados, como, os que tratavam da anistia migratória, do acesso a cargos públicos e à livre circulação de indígenas por seus territórios e nas áreas de fronteira. A nova Lei permite ao imigrante a participação sindical e em protestos e facilita a regulação migratória. Além disso, a nova Lei destaca assuntos de relevância como os princípios de não discriminação e o repúdio à xenofobia.

Apesar dos vetos, que certamente dificultarão o pleno gozo dos direitos previstos no princípio geral da nova Lei, os Direitos Humanos, é inegável que a nova Lei irá regular a entrada de estrangeiros no País e trará a responsabilidade de superar a lei, de 1980 (Estatuto do Estrangeiro), e se harmonizar com a Constituição democrática de 1988 atendendo as atuais reivindicações dos imigrantes.

\section{Considerações Finais}

O Brasil possui uma dívida histórica com relação à uma política migratória de Estado que seja coerente com a busca de uma sociedade justa e que reconheça a contribuição dos imigrantes e refugiados para o país.

O fato de os imigrantes estarem sujeitos às desigualdades econômicas regionais, ou a conflitos internos nas suas nações de origem lhes impõe a alternativa de migrar. Compõe este cenário migratório a vulnerabilidade referente à falta de documentação regularizada e a necessidade de trabalho digno para sobrevivência. Muitas vezes são submetidos à exploração do trabalho informal que se aprofunda por outras questões como as barreiras culturais e a dificuldade de falar e compreender o idioma local. Ressaltamos que um dos princípios do trabalho assalariado sob o capitalismo é o de que o capitalista tem direito ao consumo (usufruto) da força de trabalho oferecida pelo trabalhador (como mercadoria), mas não sobre a pessoa do trabalhador, ou seja, o trabalho escravo, muitas vezes vivido pelos imigrantes devido à vulnerabilidade da sua própria condição jurídica e social de imigrante.

Para que este cenário seja mudado é indispensável que os princípios de não discriminação e de igualdade de direitos, estabelecidos pelo direito internacional, sejam cumpridos perante a lei de maneira a garantir o acesso a dois aspectos fundamentais: regularização migratória e à justiça. 
Em 2016 a cidade de São Paulo sediou o VII Fórum Social Mundial de Migrações com o objetivo de destravar algumas pautas internacionais no que tange às migrações para o Brasil. O Brasil é o único país da América Latina que não ratificou a convenção da ONU sobre o direito dos trabalhadores imigrantes. Esta convenção protege as pessoas independente de sua situação jurídica no país. Além disso, o Brasil é um dos poucos países da América do Sul que não garante o direito de voto ao imigrante em nenhuma esfera política.

No entanto, há alguns anos, o Brasil vem tomando medidas humanitárias para adequar o país às normas internacionais de acolhimento aos imigrantes. Em 2009, o então presidente Lula assinou uma lei de anistia regularizando um contingente de imigrantes que tinham dificuldade de se inserir na sociedade e em 2012, o Conselho Nacional de Imigração (CNIg) editou a Resolução Normativa 97/12 que teve por objetivo regular as autorizações de permanência no país por razões humanitárias para nacionais haitianos.

A imigração haitiana foi o grande desafio para a política migratória brasileira. Embora já houvesse alguns haitianos no Brasil, só depois do terremoto de 2010 é que este fluxo migratório ganhou corpo e revelou a necessidade de se discutir políticas permanentes de inserção social do imigrante. Apesar do aumento da entrada de haitianos já em 2010, a prefeitura de São Paulo foi surpreendida pelo contingente de haitianos que chegou à cidade entre 2013 e 2014, o que levou a Coordenadoria de Políticas para Migrantes (CPMIG) a trabalhar em caráter emergencial para colocar em funcionamento aparelhos públicos capazes de atender à nova demanda.

A pressão exercida pela sociedade civil por meio dos imigrantes, ONGs, pesquisadores e instituições ligadas à igreja como a Missão Paz e a Caritas, aliada ao fomento da imprensa em retratar esta imigração, fizeram com que a partir da vinda dos haitianos, a política migratória tomasse novos rumos. Não seria possível a aprovação da Lei Municipal de Migração em São Paulo, se não fosse a atuação da sociedade civil e a gestão de uma prefeitura aberta à proposta de encontrar soluções, mesmo que emergenciais, para a questão migratória que carecia de um tratamento adequado desde a década de 1980.

No capitalismo atual o monopólio jurídico do Estado não é mais sustentado e uma regulação híbrida se faz necessária para que os anseios de determinados grupos sejam debatidos e atendidos pelas autoridades. No caso dos imigrantes, a sociedade civil organizada por meio de organizações de solidariedade contribuiu na elaboração das leis e teve poder de atuação junto à Câmara Municipal de São Paulo e na Câmara dos Deputados em Brasília. A imprensa teve um papel importante ao mostrar, mesmo que de forma exagerada e sensacionalista em muitos casos, através dos meios de comunicação, o despreparo do Estado brasileiro e dos seus órgãos públicos em tratar a questão migratória, além de acompanharem e divulgarem as dificuldades vividas pelos imigrantes em várias metrópoles brasileiras, que inclui desde a dificuldade com relação à documentação as barreiras do idioma e culturais, a luta pelo emprego e as manifestações de racismo e xenofobia reveladas pelos brasileiros. 
Estado, sociedade civil (que inclui os imigrantes) e imprensa são os três elementos básicos para a produção de uma regulação híbrida no que tange à criação da Lei Municipal de Migração para São Paulo e a Nova lei de Migração no. 13.445/17 que substituirá o Estatuto do Estrangeiro. O resultado da combinação das ações desses três atores levou à atualização das leis brasileiras referente ao tema migratório.

A regulação híbrida na concepção das novas leis migratórias trará a resolução de vários conflitos no plano legal que envolve questões e reivindicações dos imigrantes no que tange à documentação, acesso aos serviços públicos, garantia da formalidade de emprego, violação de direitos humanos dentre outras necessidades desta população e dará a eles, a possibilidade de se sentir parte da nossa população e cidadãos no Brasil.

\title{
Notas
}

\author{
${ }^{1}$ A Missão Paz é uma obra dos Missionários de São Carlos - Scalabrinianos. Com larga vivência \\ junto aos migrantes, imigrantes e refugiados em São Paulo. \\ ${ }^{2}$ http://www.justica.gov.br/noticias/governo-brasileiro-garante-direitos-para-imigrantes- \\ haitianos \\ ${ }^{3}$ http://www.justica.gov.br/noticias/governo-brasileiro-garante-direitos-para-imigrantes- \\ haitianos \\ ${ }^{4}$ http://imigrantes.webflow.io/
}

\section{Referências}

ARANGO, J. Enfoques conceptuales y teóricos para explicar la migración. Revista internacional de ciencias sociales, n. 165 , set. 2000, p. 33-47.

CARLOS, A. F. A. A condição espacial. São Paulo: Contexto, 2011.

COTINGUIBA, G.C. Imigração haitiana para o Brasil: a relação entre trabalho e processos migratórios, 2014, 154 p. Dissertação (Mestrado em História e Estudos Culturais) Universidade Federal de Rondônia, Porto Velho, 2014.

FARIA, J. E. O direito na economia globalizada. São Paulo: Malheiros, 1999. (Cap.4, pp.150-217)

GERMANI, G. Sociologia da modernização: estudos teóricos, metodológicos e aplicados a América Latina. São Paulo: Mestre Jou, 1974.

HARVEY, D. A produção capitalista do espaço. São Paulo: Annablume, 2005.

IANNI, O. Teorias da globalização. Rio de Janeiro: Civilização Brasileira, 2004.

LEFEBVRE, H. O direito à cidade. 3a .ed. São Paulo: Centauro, 2004.

MARANDOLA JR., E. Migração e geografia. In: Revista Brasileira de Estudos Populacionais. São 
Paulo, v. 28, n. 1, jun. 2011, p. 245-247. Disponível em: http://www.scielo.br/scielo. php?script=sci_arttext\&pid=S010230982011000100015\&lng=en\&nrm=iso.

Acesso em: 06 Mar. 2016.

MARTINS, J. S. Sem lenço e sem documento. O Estado de S.Paulo. 4 maio 2014. Disponível em: http://alias.estadao.com.br/noticias/geral,sem-lenco-sem-documento-imp-,1162017. Acesso em: 10 fev. 2016.

MARX, K. O capital: crítica da economia política. Vol. 1 e 2. São Paulo: Abril Cultural, 1988.

MORAES, I. A.; ANDRADE, C.A.A.; MATTOS, B.R.B. A imigração haitiana para o Brasil: causas e desafios. Conjuntura austral, Porto Alegre, v. 4, n. 20, out. nov. 2013, p. 95-114.

Portal do Ministério da Justiça e Cidadania. Disponível em: <http://www.justica.gov. $\mathrm{br} /$ noticias/precisamos-de-uma-nova-lei-de-migracoes-diz-secretario-nacional-dejustica-1>. Acesso em 07 de dez.2016

MISSÃO PAZ SÃO PAULO. Disponível em <http://www.missaonspaz.org/>.

Acesso em: 05 de dez.2016

PREFEITURA MUNICIPAL DE SÃO PAULO. Coordenação de Políticas para Migrantes. Disponivel em:

<http://www.prefeitura.sp.gov.br/cidade/secretarias/direitos_humanos/migrantes/ coordenacao/index.php? $\mathrm{p}=156223>$. Acesso em 05 de dez.2016

SANTOS, M.; SILVEIRA, M.L. O Brasil: território e sociedade no início do século 21. 16ạ. ed. Rio de Janeiro: Record, 2012.

SANTOS, M. O papel ativo da Geografia: um manifesto. Revista Território, Rio de Janeiro, ano V, no. 9, pp. 103-109,jul./dez., 2000.

SAYAD, A. A imigração ou os paradoxos da alteridade. São Paulo: Editora da Universidade de São Paulo, 1998.

\section{RESUMO}

O presente artigo tem por objetivo analisar a importância da imigração haitiana e fazer uma breve análise da atuação do Estado, da sociedade civil (ONGS, dos próprios imigrantes e dos envolvidos com a causa dos imigrantes) e o papel exercido pela imprensa que foram fundamentais para a aprovação da Lei Municipal de Migração 16.478/2016 de julho de 2016 e pela tramitação e aprovação da Nova Lei Federal de Migração no. 13.445/17.

Palavras-chave: imigração; haitianos; Estado.

\section{ABSTRACT}

The purpose of this article is to analyze the importance of Haitian immigration and to make a brief analysis of the actions of the Governement, civil society (NGOs, immigrants themselves and those involved in the cause of immigrants) and the role played by the media that were fundamental to the approval of the Municipal Migration Law 16.478 / 2016 of July 2016 and the processing and approval of the proposal of the new Federal Migration Law 13.445/17

Keyword: immigration; Haitians; Government. 